\title{
'Oh yes, robots! People like Robots; the Robot people should do something': Perspectives and prospects in public engagement with robotics.
}

\begin{abstract}
Governmental and institutional policymaking in a number of countries has embedded public engagement strategies as a primary channel to connect citizens with scientific and technological innovation. Robotics is emerging as a key site for such new technological activity and its applications are likely to be increasingly notable in our lives in coming years. Robotics researchers are investing considerable time and effort in 'engaging' publics. Concentrating on the findings of 24 qualitative interviews with those actively organising or engaging publics, across 11 public engagement activities focused on the robotics field within the UK, this paper explores their conceptions of 'public engagement', its benefits and constraints.
\end{abstract}

\section{Keywords}

Public, Engagement, Robotics, Scientists, Practitioners

\section{Introduction}

In recent years engagement has become a 'gold-standard' amongst the broad range of policymakers, scientists, the private sector and a variety of learned institutions that aim to communicate and engage with members of the public on topical issues in science and technology (Powell \& Colin, 2009; Trench, 2008; Felt \& Fochler, 2008:489). In European contexts approaches to engagement have frequently sought to become more deliberative, and inclusive in their approaches, with methods such as citizen juries, consensus conferences and science cafes taking shape with the apparent aim of promoting a greater two-way discussion with citizens about relevant scientific issues (Felt \& Wynne, 2007).

Engaging citizens with scientific issues is seen to bring several benefits. Firstly, there is a strong democratic principle that citizens will be better able to contribute to decisions that are likely to impact on their lives, and become engaged with the decision making process. 'Citizen engagement' is a key tool in public policy settings (Horlick-Jones, Rowe \& Walls, 2007), and 
replicates broader trends towards governance (Hagendijk \& Irwin, 2006), despite concern that civic engagement in general is on the decline. Secondly, there can be public caution, concern, wariness and confusion to the increasing number of scientific innovations within society. As such, anticipating public reactions can be insightful for many parties involved in the process, particularly when the field involves significant research and financial investment (Wilsdon \& Willis, 2004). Thirdly, a number of studies in recent years have highlighted the significance of public or localised knowledges in creating socially robust knowledge or research. For example, within the healthcare service, user perspectives are now routinely sought for both chronic and incidental conditions (TwoCan Associates, 2009), whilst the significance of localised contextual knowledge has been firmly evidenced (Wynne, 1996; Epstein, 1996). In addition to the policy influencing role of engagement, it has become popular in a variety of informal science settings where organisations have sought to explore how engagement might enhance the scope and/or impact of their work (Davies, McCallie, Simonsson, Lehr \& Duensing, 2009; McCallie et al., 2009; Bell, 2008).

Defining 'public engagement' is not without its challenges despite its 'normative' acceptance (Schäfer, 2009; Trench, 2008). Focusing initially on UK-based perspectives and from a research standpoint RCUK (Research Councils UK) specifically emphasizes two-way aspects:

The Research Councils use Public Engagement as an umbrella term for any activity that engages the public with research, from science communication in science centres or festivals, to consultation, to public dialogue. Any good engagement activity should involve two-way aspects of listening and interaction. (RCUK, 2009)

Goals here then include developing communication, understanding, consultation and engagement with a wider public in a mutual or interactive fashion. Despite such indicators, the perceived lack of a definitive approach has led to criticism for organisational interpretations of public engagement akin to public relations or public acceptance (Powell \& Colin, 2009; Corbyn, 2008). In America, the investigations of McCallie et al. (2009:12) established that for those 
working in informal settings, such as science centres, museums and festivals, the goals of public engagement were likely to follow one or more of the following aspects, all of which notably incorporate a sense of mutuality, empowerment, and interaction:

- Mutual learning by publics and by scientists, allowing everyone who participates to develop new or more nuanced understandings of issues and opportunities;

- Empowerment and the development of skills for participating in civic activities;

- Increased awareness of the cultural relevance of science, science as a cultural practice, and science-society interactions; and

- Recognition of the importance of multiple perspectives and domains of knowledge, including scientific understandings, personal and cultural values, and social and ethical concerns, to understanding and decision making related to science and to science and society issues.

Trench (2008) makes the point that despite such varied definitions operating, what is remarkable is how broadly accepted this notion of a two-way approach has become.

Developing activities to facilitate these broad aims of public engagement is not without practical challenges. Many of these practices can be time-consuming, expensive and require commitment. Evaluation mechanisms have been ad hoc, and there is little practical guidance in terms of how and what 'engagement' is. Numerous studies have suggested that participation and engagement are under-researched and complex processes, in particular due to the lingering framework of deficit (Irwin, 2009; Trench, 2008; Rowe, Marsh \& Frewer, 2004; Irwin \& Michael, 2003; Irwin, 2001; Rowe \& Frewer, 2000). Despite the increased inclusion of engagement mechanisms within scientific and technological policymaking, as well as by a range of other organisations, they raise a series of implications. These include the reality of their potential for bridging lay-expert divides (Chilvers, 2008; Kerr, Cunningham-Burley \& Tutton, 2007), the role of scientists (Poliakoff \& Webb, 2007; Young \& Matthews, 2007; MORI, 2000), the perceptions of citizens involved in such activities (Felt \& Fochler, 2008; Burchell, 2007), the use of engagement in commercial sectors (Burningham, Barnett, Carr, Clift, \& Wehrmeyer, 2007) and the 'translation' issue or how public engagement can most effectively feed into the 
policy process (see Horlick-Jones et al., 2007; Davies et al., 2009; Irwin, 2006; Hagendijk \& Irwin, 2006). However, there is a gap in the current literature with regards to non-policy informing engagement activities (Davies et al., 2009).

Previous studies have surveyed scientists to consider their aims, motivations and behaviours where public engagement is concerned. These insights are valuable, because, as Davies (2008:415) describes;

In practice, it is individuals or small groups of technical experts who come into contact with publics, not science as an institution or an establishment. And it is therefore the practices of individuals which will frame and shape the communication process.

Poliakoff \& Webb (2007) suggest four key factors influence scientists to participate in public engagement; past involvement in public engagement, how positive they perceive public engagement to be, how capable they feel they are at public engagement and their perception of the extent to which other colleagues are participating in public engagement. Contrary to some perceptions, there is also evidence it can aid academic activity and output (Jensen, Rouquier, Kriemer \& Croissant, 2008; Riise, 2008).

Current research has found a good number of scientists continued to prioritise public engagement as a strategy to increase information on science, its relevance and benefit to citizens (Burchell, Franklin \& Holden, 2009; Jensen et al., 2008; Classens, 2008; Davies, 2008; Royal Society, 2006). Although some scientists see public engagement as an opportunity to listen and understand the public, when asked to define public engagement in their own terms however, over a third of respondents in a recent Royal Society survey (2006) described it as a method to promote public understanding of science. When scientists are asked about potential deterrents, time, the lack of financial rewards, and impacts on career are frequently mentioned as the main disincentives (Classens, 2008; Royal Society, 2006).

Concurrently robotics research has gathered momentum in recent years, increasing likely interventions and social impacts, in addition to increasing numbers of roboticists participating in 
public engagement. Though investigating public attitudes to developments in science and technology has an extensive research history we do not have a clear indication of contemporary attitudes to potential developments in robotics specifically. Whilst some studies have examined perceptions about robotics research - the Eurobarometer series, for example, has asked questions regarding information technology and factory or fixed automation - it has been explored considerably less than other emerging fields.

Robots are being developed for use in a variety of locations, including; the workplace, home, healthcare, and the military. In the present context, robotics is most likely to impact on the lives of UK-based citizens via industrial settings. The installation of robotic machines increased considerably in the late 1990's, most prominently in auto manufacturing, though they also feature in food/beverage and tobacco production, plastics and rubber manufacturing, and the pharmaceutical industries (BARA, 2007). There are thought to be around 63,000 professional service robots in operation, for example in defence, rescue and security applications and as 'medical robots' assisting in surgery or physical therapy (International Federation of Robotics, 2009). However, robotics has not developed in ways predicted by researchers in the late 1970's, or imagined in even earlier science fiction. Artificial intelligence and autonomy has not advanced at the speed anticipated, robotic elements are often shrouded in mechanistic forms, and the definition of the terms 'robot/robotic' remains an area of academic debate today (Trevelyan, 1999).

The role of robotics in a public engagement setting has an extra dimension, since increasingly, robots themselves can 'participate' in the engagement (Breazeal et al., 2003). Engaging young people through hands-on robotic-based challenges or problem solving with Lego Mindstorm kits or the like has been suggested as a feasible path to scientific literacy (Sullivan, 2008). Similarly, a robotic mechanism or prototype can be integrated within engagement activities targeted at older groups in order that people may better grasp a realistic perspective of its capabilities. This type of technological integration within an engagement 
setting is often impractical within other fields, due to health and safety considerations, practicality or a lack of ability to perceive the developments with the human eye.

The views of individual scientists or engagers involved in these robotic engagements are insightful, since effectively they operate at the front-stage of public engagement when it is actually occurring. Likewise organisers of such activities often play a crucial role in aspects such as topics, citizen selection and facilitation which can significantly determine the impact of such events (Holliman \& Jensen, 2009; Powell \& Colin, 2009) and yet this type of 'practitioner' role is relatively under-explored (Chilvers, 2008). In this article our interest lies with these views, expressed from an 'organisational' or 'engager' perspective as to the definitions and motivations for public engagement with robotics, science and technology, in addition to the benefits and constraints they see public engagement providing. The decision for this is pragmatic, in order to explore the depth and scope of the views shared by these groups the views of other participants in the engagement process are to be reported elsewhere (Reference removed - authors named).

\section{Methods}

Aside from singular evaluations or occasional wide-scale overviews, few projects have sought to capture information across a series of unrelated but parallel activities within a distinct field of science and technology. At this stage it is important to distinguish that this project did not seek to systematically analyse, compare or evaluate the activities occurring in a normative manner in order to establish the most successful routes for participation and engagement (Rowe, Horlick-Jones, Walls, Poortinga \& Pidgeon, 2008; Kasperson, 2006) or create clearer accountability mechanisms for these types of approach (Healey, 2004), though this can be of value to the academic and science communication communities. Felt and Fochler (2008) caution that such approaches, which seek to compare and catalogue best engagement practice, may be insensitive to local cultural contexts in which participation occurs, or emphasise particularly popular and evidenced engagement methods at the cost of others that are less well known. 
Instead, this project sought to explore the types of attitudes expressed around engagement across different types of public engagement events within a single country context, the UK, and with one general topic focus, robotics.

The project team contacted robotics researchers, science centres and/or science communicators coordinating robotics-focused engagement activities across the duration of an eight-month data collection period, spanning June 2007 to January 2008, in order to fill a quota sample of 10 engagement activities. The project was able to elicit links into these communities primarily via interaction with the 'Walking with Robots' project, an EPSRC-funded network of roboticists and public engagement specialists. Eleven groups agreed to allow us to observe their projects, of which five were directly linked to the Walking with Robots project.

The project was exploratory in nature and as such has utilised predominantly qualitative methods to inform the research questions. Davies et al. (2009) highlight the multiplicity of activities that are currently occurring in a UK-context, without clear definition of what constitutes their make up or aims. In that context, of the eleven activities included in the sample there may be disagreement as to which constitute 'public engagement' in its strictest sense. Nevertheless, the activities included in the research were selected to provide similarity and contrast in terms of format, duration, target audience, levels of audience participation, venue and geographic location. They included a summer school, visions conference, expert lecture, science café, discussion events, art installation, hands-on activity workshops and science centre and museum exhibits. The level of science on offer was thus somewhat representative of the variety of approaches typically found in science communication activities, ranging from an academic level, presenting 'new' science, to 'science as fun' and a cultural activity (Riise, 2008:308). For each of the eleven projects an engagement 'activity' was observed, including repeated structured observations by multiple researchers and video recordings, building on previous work where video has been used to examine interaction in classroom and exhibition settings (Coffey et al., 2006; Heath \& Hindmarsh, 2002). The 'activity' was for many of the projects the fruition of a 
lengthy process of preparation and/or audience involvement. For some projects the engagement 'activity' occurred on a single occasion, for others it was repeated throughout a programme of work.

Interviews were undertaken with a range of participants in order to probe more deeply into participant attitudes, from the 'audience', 'engager' and 'organisational' perspectives. As Rowe et al. (2004) highlight, evaluations of participatory engagement activities often focus on the audience's attitudes, ignoring other expectations. The interviews sought to explore attitudes to the engagement experienced, reflection since the event and perception of the impact on attitudes. Semi-structured telephone interviews were carried out in the seven days that followed the event in order to allow a reflective period for participants. However for certain locations (for example at science centres and museums) it was necessary to interview participants in situ. In these situations recruiting participants was more successful when interviews were carried out immediately after the event, at the event location. This approach enabled interviews $(n=57)$ to be conducted with a range of participants, including 'audience' participants ( $n=33)$, but also 'engager' participants $(\mathrm{n}=11)$, as we have termed speakers or facilitators within activities and 'organiser' participants $(\mathrm{n}=13)$, those who were involved in the creation or organisation of an activity, from a 'back stage' perspective. We use the term 'audience' in an active sense and it should not be taken to assume that such participants were involved in only passive ways. In this article we focus on the perspectives of the 24 'engagers' and 'organisers'. The views of 'audience' participants are reported elsewhere (Reference removed - authors named) and are only provided here when they are useful to the context of the discussion.

The interview data were recorded digitally and transcribed. The transcripts were coded and analysed using the qualitative software programme nVivo. They were also made anonymous and pseudonyms are used here. A coding frame was then developed between the three researchers based on Ritchie and Spencer's (1994) five-step framework analysis. This involved a process of (i) familiarisation; initially, all of the project researchers familiarised themselves 
with a sample of the observational recordings, observation guides and interview transcripts, (ii) a thematic framework was identified; the researchers discussed and generated coding indexes for the interviews for the purpose of analysis, (iii) indexing; one researcher indexed all of the transcripts, supported by regular indexing meetings (iv) charting; the information was then collated by theme and re-indexed where necessary, and (v) mapping and interpretation.

Throughout this process the researchers set out to agree upon and negotiate common themes and key findings across each of the datasets.

\section{Results and Discussion}

\section{‘Organisers' and 'Engagers' Motivations for Public Engagement}

A wide variety of motivations were expressed by 'organisers' and 'engagers' in terms of being involved in public engagement. These included a range of issues around audience enjoyment, the provision of information, and the role of engagement in decision making and policy processes. For 'engagers' involved in activities with a range of groups and in particular young people, engagement was referred to as a route to recruitment for scientific careers, replicating traditional notions of scientific literacy. Engagers also talked however about informal and 'fun' elements. When one 'organiser' was asked by the interviewee if she had any other comments to add, she replied:

I don't know, just I think, I guess, that any kind of engagement should have an element of being enjoyable to the person as well and I think that's something we try and do here, is that, you know, it's not all about, you know, what are the issues, but people come here to have fun, so I guess that's something that we're quite interested in taking forward as well. (Jenny, Organiser, Activity 2: Robotics exhibits at a Science Museum)

For those working to engage young people or in more relaxed environments, this 'fun element' was something they were particularly conscious of and an aspect which has been recognised elsewhere (Ward, Howdle \& Hamer, 2008). Here, Mike, an 'engager' involved in the organisation and delivery of a Robotics Summer School had discussed a number of the practical problems attached to such activities, such as equipment not working, having to purchase 
additional kit and the complexity of transporting such materials in Central London, before reflecting on a further point:

...But one bit though...in terms of the actual, all my days themselves, is that I try and make them fun days, it's gotta be, I wanna see happy bunnies at the end of the day... there really has got to be a fun, showmanship type of element in it all...because every time I go out and talk to people that's actually one of the first things I actually mention...it's really got to be a fun day, you've got to communicate to them, and if you can't do that it doesn't matter if you know the subject inside out, you're not going to do it [engage them]. (Mike, Engager, Activity 3: Robotics 'Summer School')

In addition to these more informal aspects the interviews provided an opportunity to explore the types of functions public engagement could have in wider policymaking. A range of 'engagers' and 'audience' participants discussed a democratic role that people could take in providing their views on science and technology. From the 'engager' perspective, comments here often alluded to 'audiences' having the 'correct' or 'accurate' information on which to base such decisions in their role as voters but also related to the intended audience that specific activities were targeting.

People don't make very good decisions but at least if you can expose or you know expose them to all the arguments sensibly then I think the really important people are the opinion formers...this comes back to the science café, okay it is the middle class intellectual types that attend but if you are actually trying to educate usefully and you've only got a room that can hold 100 people then you know maybe that is the audience you need, or the useful audience. (James, Organiser, Activity 10: Science Café on Artificial Intelligence)

I genuinely think that, you know, public understanding of science is a good thing. Um...so it's something that, as a scientist, one should try and do is communicate to the public what you do and why you do it. (Cecile, Engager, Activity 6: Robotics Expert with Demonstration)

Cecile's comments used the terminology of 'public understanding' to express a supportive stance to increased public communication, but also drew out a sense of responsibility amongst the scientific community to do public engagement. Comments about the need to have informed decision making frequently referred to the traditional notion that experts are best placed to provide this type of balanced information, to present 'both sides of the argument' or to 'educate' prior to decisions being made, findings which echo other work in the field (Holliman \& Jensen, 
2009; Davies, 2008). In contrast, in our interview data from 'audiences' it was notable that many 'audience' participants actively rejected this notion of their having a role in influencing decision making, for reasons including: a lack of desire, interest or concern; even being too old for such decisions - which, it was argued were best left to younger, future generations who were likely to witness the greater impact of robotics or new innovations (Reference removed authors named).

Some participants identified economic motivations for a wider policy incentive to encourage public engagement, referring to the need for a broader scientific literacy to encourage scientific careers and economic competitiveness. There were a number of comments that saw engagement fulfilling a 'public understanding of science' agenda, despite the researchers avoiding this terminology, whereby its key requirement or motivation was identified as providing an educational or informative role to a passive public (Holliman \& Jensen, 2009; Cook, Pieri \& Robbins, 2004). As such both 'engagers' and 'audience' members alike prominently discussed a role they felt they occupied to provide information, from being aware of emerging developments in the world, to raising awareness specifically about robotics:

Just raising the awareness of it, as a topic of conversation, not necessarily as a good thing or a bad thing... having people talk about working, living, living with robots, working with robots. (Jenny, Organiser, Activity 2: Robotics Exhibits).

There was an expectation that people participated to receive information and it was not always the case that 'engagers' or 'audiences' identified with or were personally motivated to be involved in a more two-way process.

One activity involved a more pivotal policy relationship, though even here, at this stage of the process the expectation of its influence was less than clear to the 'organiser' involved:

We've a policy department, which does pro-active and re-active communications with, with various government departments, and policy making decision makers and...[we] would like to explore the value of public engagement in sort of, informing policy, and so it doesn't have, it's not a big sort of deliberative exercise for us, where we definitely know that it's going to influence policy or anything like that, it's more...exploring 
different activities in which we can gather um, public opinion, views, issues and concerns on the themes and topics that we're studying, but it's, it's a really sort of scoping area at the moment for me to start building up relationships with my policy team and sort of raising awareness of public engagement and the different ways that we can use that. (Hannah, Organiser, Activity 9: Robotic Visions Conference)

Hannah's comments indicate that for some of those involved in such processes the short-term and policy-driven nature, we should be doing engagement so we will, of such activities can impair their meaningful development and recognition of wider impacts (Powell \& Colin, 2009). Some interviewees expressed scepticism regarding how public engagement worked in practice, identifying it as a somewhat cynical or rhetorical device. 'Engagers' cast doubt on how engaged (UK) citizens tended to be in these types of processes or how it worked in practice and what impacts could be calculated:

I have to admit that sometimes I am unclear when I see public engagements of, of science, if people actually do know where it's going, if you follow me...they, you know, oh, we're got adults in here [attending], therefore, that's the end of the trail, and I think to myself, oh, what is the point of that (Mike, Engager, Activity 3: Robotics 'Summer School')

There was concern about the extent to which scientists or policymakers listened to public concerns, with occasional phrases such as 'tried to convince' used by engagers to describe the activity they had participated in. Interview questions around the wider impacts of public engagement were often met with a good deal of uncertainty amongst all three groups interviewed, along the lines of 'that's difficult', 'that's a tough one', 'hmm', or 'I will need to think about that'. The participants' reactions indicated that this was not a rejection of the way the questions were worded but difficulty with identifying that type of broader objective in the work that they were doing, perhaps due to the 'ritualistic' or 'diversionary' manner via which some of these approaches have been adopted (Irwin, 2006). Across all groups there appeared to be a lack of ability to make the connection between 'local' or individual (Davies, 2008) activities they were or would participate in, and how that could be part of a bigger picture of wider civic engagement. Significantly, this confusion around the role that public engagement may have can lead to uncertainty for all parties that are involved (TwoCan Associates, 2009). 
In general, comments on behalf of 'organisers' and 'engagers' were 'politically correct' in recognising the expert role of publics, in contrast to other work which has sometimes suggested a more degrading view of publics (Burchell, 2007).

You don't have to have a bunch of degrees after your name to, you know, have opinions, and to be able to think, you know rationally and logically and, and um, and to express yourself and to be able to engage in useful and meaningful dialogue. (James, Engager, Activity 1: Robotics Expert lecture + Q\&A)

Other perceptions of publics were however expressed and a novel contradiction arose between 'engagers' recognition that the lay people they were engaging with were well versed, skilled and literate (Triese \& Weigold, 2002), and their more generalised comments about the need to educate or inform. A number stressed that involvement in a 'public' activity did not mean there was no or limited expertise in participants' backgrounds. Despite this 'engagers' simultaneously had low expectations of those they were interacting with. At the expert lecture, science café and discussion activities some very complex and technical questions were posed and 'engagers' often noted these types of 'sophisticated questions' with some surprise.

Robotics was identified by interviewees as specifically having relevance for public engagement for a variety of reasons including its attractiveness, hands-on nature and the relatively positive public interest surrounding the field. This positive perception of its role in public engagement was somewhat to be expected as the 'engagers' tended to have expertise in the field of robotics. In the opinion of 'organisers' and 'engagers,' robotics was seen to be of interest to young people and 'audiences' in general. For a number of engagers, young people were identified as finding robotics events 'compelling and attractive'. Young people's inherent interest in robotics was portrayed as a way of attracting them to engineering and science and mapped onto to traditional notions of the need for a greater scientific literacy.

I think if, if, if you don't have anyone interested in the science of the technology or whatever it happens to be, that's not then passed on to the youngsters and then they miss an opportunity. I'm not suggesting at all that everyone's going to go into robotics or 
science, but I think that, the name of the game now is making sure that everybody's got an opportunity to see what can be done and not done, and then, if you actually engage adults via their children with a bit of luck, what you're seeing then is that they can see the possibilities of what might be obtained, but if they go and do anything about it or not is a different thing all together of course. (Mike, Engager, Activity 3: Robotics 'Summer School')

I think they [people] just need to know that it's [building a robot] not something that's beyond an interested amateur to do, nowadays, it used to be, but it's not anymore, we built some robots here, in our office, so there's no reason why anybody who wants to have a robot can't have one now, um, and I think that is why... that one day they will be everywhere, and like, like a few years ago people who knew how to work computers were the ones who were a bit geeky, and now they're the one's who've got really lovely paid jobs and, you know, everyone's calling them going, fix my computer for me. In a couple of years when everyone's got a robot people who know how to fix them will be the ones who're most employable probably. (Dan, Organiser, Robotics exhibits at a Science Museum)

For 'organisers' robotics was suited to engagement as it could often provide technology or equipment that can be relatively amenable to providing hands-on activities. In addition, both 'organisers' and 'engagers' involved in some of the activities talked about finding the topic of robots interesting and stimulating themselves. Here an 'engager' involved in the Robotic Visions conference with young people, who was participating due to her expertise in facilitation as opposed to the subject matter, discusses this point after the interviewer asks 'What was your reaction to the robotics topics that came up?':

It was fantastic, because I must admit, I'm somebody who doesn't, I don't go in for science fiction, I'm really not into any of that kind of futuristic stuff, I just don't follow it. I suppose, I'm going to sort of bring in gender stereotypes, I'm not, I've never really thought of myself as scientific, I've never been good at it, and all the rest of it, so it's never been me. So I was pleasantly surprised, I think, to feel that I could engage with it, on a level that, that it was okay for me, I didn't feel overwhelmed by it, and that, that had been my worry as a moderator, thinking that I'm supposed to be sort of one level ahead of the people I'm moderating. (Pat, Engager, Activity 9: Robotics Visions Conference)

Similarly this 'engager' from a science centre described her interest in the topic:

It was obviously just quite exciting to use all these robots as well, that you wouldn't normally get your hands on. (Sophie, Engager, Activity 5: Robotic Show/Presentation) 
'Organisers' and 'engagers' described robotics as generally being of public interest 'everyone loves a robot story', it being topical and contemporary and linking to science fiction or areas people could relate to. For one 'engager' this had significant implications:

Cecile: Whenever anyone says [in the department] oh we must do something for the public, everybody immediately says, oh yes, robots! People like robots. The robot people should do something.

Interviewer: And how do you feel about that?

Cecile: Um...I have mixed reaction to that because I think they're right that robots are much more, you know, immediately engaging than any other obvious thing you can do...but on the other hand it does tend to be a bit unfair in terms of who has to do the work... people always want the robots to do things. (Cecile, engager, Activity 6: Robotics Expert with Demonstration)

For Cecile, the novelty of the research field, and her confidence as an 'engager' could be seen as potential deterrents for becoming over-exposed in terms of her involvement with public engagement, but her comments also raise interesting notions of robotics being a somewhat 'safe' option via which a university might seek to publicise their work. In contrast to some other areas of science and technology, it was thus noticeable that 'organisers' and 'engagers' alike saw robotics as occupying a secure subject area for discussion. Should the area come under increased media or public focus in future years, it will be interesting to see if this positive perception remains.

\section{The Benefits for 'Organisers' and 'Engagers' of Public Engagement}

'Organisers' and 'engagers' were keen to discuss the benefits that they personally felt following involvement in public engagement, including career-based factors, personal enjoyment and thinking about their research in new or novel ways. The findings suggest that for both 'engagers' and 'organisers', a professional or pragmatic choice frequently governs their motivation to participate; it was part of their job role or added to a CV and many were, as such, versed in the language of engagement with a personal incentive to become more involved in such activities. It is recognised that scientists rarely identify a strong career motive to participate 
in such events, however the data presented here suggests that despite this some still see it as an implicit benefit due to their increased career satisfaction. In contrast to other studies the majority of 'engagers' involved did not suggest a particular motivation to 'self-promote', attract attention from decision makers or set agendas (Treise \& Weigold, 2002), instead 'engagers' frequently suggested additional, incremental factors came into play, which gave them a degree of personal satisfaction and enjoyment (Burchell et al., 2009; Pearson, Pringle \& Thomas, 1997).

'Organisers' and 'engagers' stressed that they wanted to make activities entertaining and enjoyable, informative but still 'fun' and suggested an element of personal 'performance':

I never get bored with it [talking to people], and I suppose that's partly because of the performance in the sense that for me, this was true even when I used to, to lecture in front of classes of students, every lecture, or every talk is a gig as far as I'm concerned...I enjoy the performance aspect of it. (James, Engager, Activity 1: Robotics Expert lecture + Q\&A)

The comments made by James drew comparisons to both performing and teaching elements. Aside from educational motivations, 'engagers' also suggested they were keen to hear new views, to discover alternative perspectives on their work or renew their own enthusiasm for their subject, as James continued:

When I give talks, even when I've given them a lot before...I'm always re-energised. If I'm feeling a bit down or a bit low on energy, or intellectual energy, I talk about this stuff, and, and I myself think, wow this is really exciting stuff isn't it.

Interviewer: (laughs) so it renews your enthusiasm?

Yeah, so I personally become re-excited or re-energised by this whole thing.

Interviewer: Interesting, so there's a sort of exchange then, there's a sort of energy exchange then between you and the audience?

Yeah definitely...I definitely come away, I get just as much out of it as I put into it, and often more, in the sense that I, I think it's, you know, it's a good trade. (James, Engager, Activity 1: Robotics Expert lecture + Q\&A)

For James, being involved in an engagement activity affects the 'engager' as well as the publics involved. This theme was continued by a second 'engager': 
I have personally found that a lot of times, that good questions that you get from people outside your own field can really make you examine some of your assumptions...it's regions that you wouldn't have explored intellectually because of your sort of academic history. (Janet, Engager, Activity 10: Science Café on Artificial Intelligence)

Here, both James and Janet reflected on the personal benefits they felt. For Janet the questions posed during engagement provided an opportunity for her to reconsider her own research area, outside of the normal disciplinary constraints, suggesting an openness to engage with the other cultural values that publics can provide (Young \& Matthews, 2007). For the organiser involved in the Visions Conference, despite some uncertainty around the likely impact of the activity discussed in an earlier quote, she shared a positive opinion on the views shared:

It exceeded my expectations...I think we got a lot from the young people because it was very sort of, in some ways it was very sort of deliberately vague... we were sort of wanting to create the platform for the young people to lead us, rather than leading them, so you never know if you're actually going to get [anything] tangible out of it, and we just transcribed the flipcharts actually, and we certainly have, there's certainly information there that will be interesting and can inform debate around these issues, as well as the debate that happens, you know, with the higher levels and the powers that be, I think there were some really interesting insights. (Hannah, Organiser, Activity 9: Robotics Visions Conference)

Hannah's comments indicate that she too had been surprised by some of the information provided, but also refer to a certain sense of frustration for those involved in organising or facilitating such activities as to the likely extent of their influence. Despite the positive impressions of the information provided, the 'organiser' went on to suggest that in future they would seek to consider the stimulus material more, in a similar fashion to some of the prior comments discussed:

There might be things that I would do differently. Rather than leave it entirely to the young person's vision to develop upward, what they would like to talk about, I would like to probably do a bit more informing, and not, not to bias them...but they can't discuss what they're unaware about...and there might be...some aspects of robot technology that weren't touched upon because they essentially didn't know the research was going on. (Hannah, Organiser, Activity 9: Robotics Visions Conference) 
Other 'engagers', who were mostly experts in their field, but occasionally novices to public engagement, suggested a similar keenness to extend their own personal awareness, not of their specific field, but of engagement techniques:

I think the two groups [robotic designers and members of the public] coming together it does create a perfect setting for bringing these ideas to the public domain so I was very interested to see how it [engagement] went from that point of view, how you can get the public engaged with the science and the technology, how you communicate it, how they can engage with it, and how you generate feedback from that, so it was really interesting for me just to see how the whole thing played out. (Kevin, Engager, Activity 11: Discussion Events in Science Café Style)

Kevin then expressed a desire to extend his awareness of the engagement process itself. The idea that 'audience' members could provide something for experts was expressed most frequently however, in the context that 'audiences' could provide additional questions, a certain level of naivety or wider perspective which might highlight to experts other considerations or avenues of work. There was some evidence then that communication has moved on from 'engagers' taking solitary responsibility for framing the questions for debate. However, our analysis of our observations suggested that in some traditional engagement settings common organisational techniques, such as the time allowed for discussion or environmental factors, continue to construct boundaries around the opportunities participants have to interact.

'Organisers' and 'engagers' mentioned the value of having 'real experts', and expert interaction, as key to successful public engagement. Interviewees suggested that the presence of 'real experts' served to demystify science, create an interaction and provide role models. Interestingly, from the 'audience' perspective the opportunity to meet experts and scientists was often taken as granted and 'audiences' frequently had expectations regarding what an 'expert' should encapsulate (Reference removed - authors named); only in the Visions Conference did students describe being in awe of and impressed by the 'experts' that had participated. Whilst expertise impacted on the interactions in other ways, it is notable that 'engagers' and 'organisers' saw this as 'added value' for participants, whereas for 'audience' members it 
simply fulfilled an expectation. In general, from our observations it is clear that the activities included in this project ran smoothly with regards to personal interactions, with questions posed in a respectful way and 'engagers' and 'audience' members alike suggesting they felt comfortable and empowered. However, for discussion-based activities, moving from a 'Q\&A' to discussion amongst groups was often reported as problematic; in some of the science centre work it was refreshing to see that the hands-off approach by 'engagers' often resulted in some lengthy individual discussions motivated by 'audience' members.

\section{'Organisers' and 'Engagers' Constraints to Public Engagement}

Despite the recognition of a number of advantageous aspects of engagement there were also recurring constraints centred largely around a variety of organisational issues and assumptions of prior engagement awareness or experience. A range of practical and perceptual issues emerged as impacting on the engagement experienced. In particular, facilitation was crucial to activities such as science cafés and discussions:

Everyone felt from feedback from the speakers that it wasn't enough time to really go into issues, but there was some very kind of, in my sessions at least, some very lively contributions...we will in future moderate each session... I think it really would have benefited from, a moderator in each space, because there were some people who dominated (Peter, Organiser, Activity 11: Discussion Events in Science Café Style (with experts present))

Here 'organisers' reflected on financial constraints, whereby there were often limited budgets to employ experienced facilitators or a failure to recognise in advance their necessity. Having a skilled facilitator or moderator could also relieve some of the pressure 'engagers' felt, to take questions or try and build a discussion. Whereas in a public discussion activity a hard line on facilitation could be taken - or 'crowd control' as one 'engager' coined it - in activities with other groups a much 'softer touch' was seen as valuable. In workshop activities, the summer school and some exhibits visited, the value of sitting back and waiting for the participant to approach and control the interaction was highlighted:

The robotics co-ordinator, had a particular style...he lets them use their imagination to get on with it. Although he's there hovering in the background to help...he's not coming 
at them and telling them what to do, and I like that approach, because it then teaches the boys responsibility for their own learning. (Ben, Organiser, Activity 3: Robotics 'Summer School')

Ben's comments support work suggesting that such social learning is a key benefit of engagement activities, allowing the participant to become self-directive, receiving broader educative benefits even if they are unintentional (Davies et al., 2009).

'Organisers' discussed how 'engagers' skills could impact on activities; to ameliorate this issue they highlighted grilling potential experts on the phone in advance or checking their past experience to gauge how well they could engage an 'audience'. Both 'engagers' and 'organisers' also discussed 'audience' reaction - that 'audiences' could sometimes be quite serious and formal - making engaging in a more casual method difficult.

It's hard to always to read a British audience, I think they are a little more quiet than American audiences but they were certainly very interested. I mean the room was full of people that were looking at me the whole time, they weren't like drinking and talking about other stuff, so obviously they were extremely engaged. (Janet, Engager, Activity 10: Science Café on Artificial Intelligence)

Once the 'engagers' had been selected 'organisers' generally appeared to take something of a laid back approach to preparing and briefing 'engagers', leaving the 'interpretation' up to them. This perhaps did not fully utilise the opportunity to ensure that the 'engagers' content and approach was best suited to the activity in question. Poor briefing was however mentioned in some cases by 'engagers' involved in the activities, who felt more planning or understanding of the activity would have improved that which occurred. In some cases there was limited time to provide such briefing and feedback for one-off activities or events, particularly when for a number of 'engagers' this formed something of an add-on to their work. Preparation levels varied and some 'engagers' mentioned modifying existing activities they had previously delivered. 'Organisers' made an assumption or took confidence that someone who is an expert or well-versed in public speaking would not need additional support or advice: 
I spoke to the facilitator. He knew what to say about the people that were there, so that all seemed fine. The only downside was I hadn't sent a briefing document to the facilitator beforehand which would have helped, but he's a very experienced facilitator, so he was able to take notes at the briefing meeting of what everybody was doing so was able to take over, was able to facilitate very well. (Paul, Organiser, Activity 11: Discussion Events in Science Café Style)

However these types of assumptions that a general level of expertise and confidence would get people through fails to recognise that public engagement activities can have differing requirements. As Riise (2008:304) highlights organisers can create negative experiences by 'not taking into account the presentation skills, talents and interest of the scientist.' On the other hand those 'organisers' that were more directive also referred to 'engagers' disregarding instruction, suggesting that the level of confidence amongst 'organisers' and 'engagers' alike in their related skills could sometimes detract from the quality of the engagement. It was notable that for interviews where training or effective briefing had occurred it was a non-issue, whereas for those lacking in such support it had a tendency to dominate the content of the interview or provide an additional, central and functional 'barrier' to engagement (Davies et al., 2009; Pearson et al., 1997).

One 'organiser' suggested that speakers were selected based on the topics that he thought were of most interest, whilst at the same time recommending a very active role on the part of the audience:

Really I was hoping for some dialogue to take place where people were discussing that in the course of the event, so that people were looking at how you are getting this merger between biological and mechanical, and thinking how this is going to affect their lives in the future... the event is very audience led, so, all you can do is present examples of this to them....and then let the audience decide what they want to discuss about those subjects. (Paul, Organiser, Activity 11: Discussion Events in Science Café Style)

Here Paul appeared to traverse a difficult boundary between organising and planning events according to his notions of what topics are of interest, whilst avoiding guiding the audience too far. Powell and Colin (2009) similarly note that as 'organisers' this role can be complex and changeable, with contrasting expectations and negotiations as to how much guidance such roles require. It was notable that those 'organisers' or 'engagers' working within the setting full-time 
or with an allocated time allowance within their professional roles appeared to work to more realistic deadlines or build in preparation time. Past collaboration obviously aided this aspect for some 'engagers' and 'organisers'. Others used the opportunity to work on an engagement activity as a collaboration prospect in itself, either for future engagement activities or to meet fellow experts as has been found elsewhere (Ward et al., 2008; Pearson et al., 1997). However, as with briefing and feedback, relationships in some cases were not easy, in particular in at least two activities collaborators felt that their expectations of each other had not been met and this had a negative impact on the quality of the activity.

\section{Conclusions}

A number of interesting issues have arisen within this limited number of interviews carried out with UK 'engagers' and 'organisers' seeking to engage publics with robotics. On a positive note it was worth highlighting that certain issues previously identified as problematic in public engagement such as career barriers, language use, a determination for consensus and level of 'audience' understanding, were not consistently raised by 'engagers' or 'organisers' (Davies, 2008; Young \& Matthews, 2007; Cook et al, 2004; Treise \& Weigold, 2002). However, organisational factors continue to impact on the quality of engagement, and tied to this it appears important that the aims for specific engagement activities are clear for all participants

rather than distorted by popularised notions of engagement, in order that 'audience' expectations are met and 'engagers' feel capable in their preparation and delivery. As Horst (2008:272) has described in the context of consensus conferences, 'there is ample scope for disappointment and frustration if participants and organizers do not share the same expectations about the outcome' and we witnessed this in a number of the activities included here.

There was a notable openness amongst 'engagers' and 'organisers' to engage in research of this type, including opening themselves up to external observation. This suggests that a considerable research opportunity exists within the day-to-day informal science engagement activities occurring across the UK and in other countries for future work of this type. It was also 
positive to find that for many of the 'engagers' involved, the more individualised dynamics posing individual questions, or participating in incidental interactions - were recognised as beneficial. This provides supporting evidence of the 'engagers' value for more individualised approaches as incremental steps to changes in the relationships between science and society (Davies et al., 2009). Whilst individualised approaches may impact on feasible audience sizes, and therefore total numbers reached may be low for some engagement activities, this research suggests significant key benefits which are not realistic on a larger scale.

Referring back to the aims of engagement suggested in the work of McCallie et al. (2009) engagers did more frequently express motivations around mutual learning and multiple perspectives, but wider empowerment of citizens and society in general via participation in such 'local' activities was often unclear or missing. Additionally, practical issues such as a lack of preparation, appropriate time, good facilitation or audience expectations can impact on the intention to offer opportunities for two-way aspects of listening and interaction (RCUK, 2009). However the subtle recognition amongst 'engagers' and 'audiences' of key benefits of two-way communication suggested intentions to be involved in a more mutual conversation.

Whilst 'engagers' and 'organisers' occasionally suggested a discreet expectation that communicating about robotics might increase recruitment to the field, they did not envisage an expectation to inspire only positive perspectives or promote one-way talk (Davies, 2008). Instead, a capacity to question and debate the desirability of robotics was referred to, even if that capacity was not always recognised amongst 'audience' participants or in the events themselves. The findings examined here support suggestions that despite extensive conversing or the 'grand narrative' of public engagement amongst a variety of organisations (Trench, 2008:120), much talk around more participatory engagement activities is entrenched by cultural habit around notions of public understanding which will not evaporate rapidly (Davies et al., 2009; Davies, 2008; Irwin, 2006; Cook et al., 2004). This adds to the assumption amongst some 'engagers' and 'organisers' that past teaching or educative experience will result in engagement (MORI, 
2000), rather than re-thinking the skills, content or framing it requires. We recognise the point made by Holliman and Jensen (2009) that it is difficult to ascertain whether such practices are active and explicit, but agree that the underlying assumptions and tendencies towards onedirectional formats could create a self-limiting function amongst organisers and engagers to remain within their comfort zones.

The 'engagers' and 'organisers' involved in these interviews were limited to one field, robotics, where public attitudes remain discreet and broad. At this time they were keen to engage about their field, a field with a wealth of futuristic scenarios ripe for the public's imagination. However, should robotics face future media or public controversy the attitudes of those 'engagers' involved are likely to be significantly altered (Cook et al., 2004). The positive perception of those involved at present may be due to their individual agendas being supportive of public engagement notions but likewise it adds credence to the argument that one size does not fill all where engagement is concerned (Trench, 2008). Instead, the shifts between public understanding and public engagement, deficits and dialogues can be more readily identified as a co-existence (Bucchi, 2008; Hagendijk \& Irwin, 2006). Scientists do not operate with one definition of public engagement (Davies, 2008), instead moving between flexible, diverse and disjointed notions suggesting that 'engagers', 'organisers' and 'audiences' alike will change their engagement agendas if and when controversies arise. Like the robotics research these activities were based on, it seems engagement has not developed at the speed anticipated, innovative elements are often shrouded in traditional forms, and the definition of the term engagement remains an area of both academic and practical debate today.

\section{Acknowledgments}

This research was funded by the Economic and Social Research Council (RES-000-22-2180). The authors would also like to thank the individuals and organisations who allowed us to observe their activities and participated in interviews. 


\section{References}

BARA (2007). Results for the Annual Survey of UK Robot Installations for 2007. British

Automation and Robot Association. Coventry: University of Warwick. Retrieved from http://www.bara.org.uk/info/statistics/Industrial_Robot_Facts_2007.pdf

Bell, L. (2008). Engaging the public in technology policy: A new role for science museums. Science Communication, 29, 386-398.

Breazeal, C., Brooks, A., Gray, J., Hancher, M., McBean, J., Stiehl, D., \& Strickon, J. (2003). Interactive robot theatre. Communications of the ACM, 46, 76-84.

Bucchi, M. (2008). Of deficits, deviations and dialogues: theories of public communication of science. In M. Bucchi \& B. Trench (Eds.), Handbook of Public Communication of Science and Technology (pp. 57-76). Abingdon: Routledge.

Reference Removed - Authors Named

Burchell, K. (2007). Empiricist selves and contingent 'others': The performative function of the discourse of scientists working in conditions of controversy. Public Understanding of Science, 16, 145-162.

Burchell, K., Franklin, S., \& Holden, K. (2009). Public Culture as Professional Science: Final Report of the ScoPE Project (Scientists on public engagement: From communication to deliberation?). London: BIOS (Centre for the Study of Bioscience, Biomedicine, Biotechnology and Society). Retrieved from http://www.lse.ac.uk/collections/BIOS/scope/pdf/scope_final_report.pdf

Burningham, K., Barnett, J., Carr, A., Clift, R., \& Wehrmeyer, W. (2007). Industrial constructions of publics and public knowledge: A qualitative investigation of practice in the UK chemicals industry. Public Understanding of Science, 16, 23-43.

Chilvers, J. (2008). Deliberating competence: Theoretical and practitioner perspectives on effective participatory appraisal practices. Science, Technology and Human Values, 33, $421-451$. 
Classens, M. (2008). European trends in science communication. In D. Cheng, M. Claessens, T. Gascoigne, J. Metcalfe, B. Schiele, \& S. Shi, (Eds.) Communicating Science in Social Contexts: New models, new practices (pp. 27-38). New York: Springer.

Coffey, A., Renold, E., Dicks, B., Soyinka, B., \& Mason, B. (2006). Hypermedia ethnography in educational settings: possibilities and challenges. Ethnnography and Education, 1, $15-30$.

Cook, G., Pieri, E., \& Robbins, P. T. (2004). The scientists think and the public feels: Expert perceptions of the discourse of GM food. Discourse and Society, 15, 433-449.

Corbyn, Z. (2008). Nottingham raises eyebrows over definition of 'public engagement'. Times Higher Education. Retrieved from http://www.timeshighereducation.co.uk/story.asp?storycode=403234.

Davies, S. R. (2008). Constructing communication: Talking to scientists about talking to the public. Science Communication, 29, 413-434.

Davies, S. R., McCallie, E., Simonsson, E., Lehr, J. L. \& Duensing, S. (2009). Discussing dialogue: Perspectives on the value of science dialogue events that do not inform policy. Public Understanding of Science, 18, 338-353.

Epstein, S. (1996). Impure Science, AIDS, Activism and the Politics of Knowledge. Berkeley: University of California Press.

Felt, U. \& Fochler, M. (2008). The bottom-up meanings of the concept of public participation. Science and Public Policy, 35, 489-499.

Felt, U. \& Wynne, B. (2007). Taking European Knowledge Society Seriously: Report of the Expert Group on Science and Governance to the Science, Economy and Society Directorate, Directorate-General for Research, European Commission. Brussels: Directorate General for Research Science, Economy and Society. Retrieved from http://ec.europa.eu/research/science-society/document_library/pdf_06/europeanknowledge-society_en.pdf 
Hagendijk,R. \& Irwin, A. (2006). Public deliberation and governance: Engaging with science and technology in contemporary Europe. Minevra, 44, 167-184.

Healey, P. (2004). Scientific Connoisseurs and Other Intermediaries: Mavens, Pundits, and Critics. Swindon: ESRC. Retrieved from http://www.esrc.ac.uk/ESRCInfoCentre/about/CI/CP/Social_Sciences/issue59/mavens.as $\mathrm{px}$

Heath, C. \& Hindmarsh, J. (2002). Analysing interaction: Video, ethnography and situated conduct. In T. May (Ed.) Qualitative Research in Action (pp.99-121). London: Sage.

Holliman, R. \& Jensen, E. (2009). (In)authentic sciences and (im)partial publics: (re)constructing the science outreach and public engagement agenda. In R. Holliman, E. Whitelegg, E. Scanlon, S. Smidt, \& J. Thomas (Eds.) Investigating Science Communication in the Information Age: Implications for public engagement and popular media (pp.35-52). Oxford: Oxford University Press.

Horlick-Jones, T., Rowe, G., \& Walls, J. (2007). Citizen engagement processes as information systems: The role of knowledge and the concept of translation quality. Public Understanding of Science, 16, 259-278.

Horst, M. (2008). In search of dialogue: Staging science communication in consensus conferences. In D. Cheng, M. Claessens, T. Gascoigne, J. Metcalfe, B. Schiele \& S. Shi, (Eds.) Communicating Science in Social Contexts: New models, new practices (pp.259274). New York: Springer.

International Federation of Robotics (2009). World Robotics 2009 Service Robots. Executive Summary. Frankfurt: IFR Statistical Department. Retrieved from http://www.worldrobotics.org/index.php

Irwin, A. (2001). Constructing the scientific citizen: science and democracy in biosciences. Public Understanding of Science, 10, 1-18. 
Irwin, A. (2006). The politics of talk: Coming to terms with the 'new' scientific governance. Social Studies of Science, 36, 299-320.

Irwin, A. (2009). Moving forwards or in circles? Science communication and scientific governance in an age of innovation. In R. Holliman, E. Whitelegg, E. Scanlon, S. Smidt, \& J. Thomas (Eds.) Investigating Science Communication in the Information Age: Implications for public engagement and popular media (pp.3-17). Oxford: Oxford University Press.

Irwin, A. \& Michael, M. (2003) Science, Social Theory and Public Knowledge. Maidenhead: Open University Press.

Jensen, P., Rouquier, J., Kreimer, P., \& Croissant, Y. (2008). Scientists who engage with society perform better academically. Science and Public Policy, 35, 527-541.

Kasperson, R. E. (2006). Rerouting the stakeholder express. Global Environmental Change, 16, $320-322$.

Kerr, A., Cunningham-Burley, S. \& Tutton, R. (2007). Shifting subject positions: experts and lay people in public dialogue. Social Studies of Science, 37, 385-411.

McCallie, E., Bell, L., Lohwater, T., Falk, J.H., Lehr, J. L., Lewenstein, B. V., Needham, C., \& Wiehe, B. (2009). Many Experts, Many Audiences: Public Engagement with Science and Informal Science Education. A CAISE Enquiry Group Report. Washington D.C.: Center for Advancement of Informal Science Education (CAISE). Retrieved from http://caise.insci.org/uploads/docs/public_engagement_with_science.pdf

MORI (2000). The Role of Scientists in Public Debate. London: The Wellcome Trust. Retrieved from

http://www.wellcome.ac.uk/stellent/groups/corporatesite/@msh_peda/documents/web_d ocument/wtd003425.pdf

Pearson, G., Pringle, S.M., \& Thomas, J. N. (1997). Scientists and the public understanding of science. Public Understanding of Science, 6, 279-289. 
Poliakoff, E. \& Webb, T. L. (2007). What factors predict scientists intentions to participate in public engagement of science activities? Science Communication, 29, 242-263.

Powell, M. \& Colin, M. (2009). Participatory paradoxes: Facilitating citizen engagement in science and technology from the top-down? Bulletin of Science, Technology and Society, $29,325-342$.

RCUK (2009). What is public engagement? Retrieved from http://www.rcuk.ac.uk/cmsweb/downloads/rcuk/scisoc/peupdate.pdf.

Riise, J. (2008). Bringing science to the public. In D. Cheng, M. Claessens, T. Gascoigne, J. Metcalfe, B. Schiele \& S. Shi, (Eds.) Communicating Science in Social Contexts: New models, new practices (pp.301-309). New York: Springer.

Ritchie, J, \& Spencer, L. (1994). Qualitative data analysis for applied policy research. In A. Bryman \& R. G. Burgess (Eds.) Analysing Qualitative Data (p.173-194). London: Routledge.

Royal Society (2006). Science Communication: Survey of Factors Affecting Science Communication by Scientists and Engineers. London: Royal Society. Retrieved from http://royalsociety.org/page.asp?id=3180

Rowe, G. \& Frewer, L. J. (2000). Public participation methods: A framework for evaluation. Science, Technology and Human Values, 25, 3-29.

Rowe, G., Marsh, R. \& Frewer, L. J. (2004). Evaluation of a deliberative conference. Science, Technology and Human Values, 29, 88-121.

Rowe, G., Horlick-Jones, T., Walls, J., Poortinga, W. \& Pidgeon, N. F. (2008) Analysis of a normative framework for evaluating public engagement exercises: reliability, validity and limitations. Public Understanding of Science, 17, 419-441.

Schäfer, M. S. (2009). From public understanding to public engagement: an empirical assessment of changes in science coverage. Science Communication, 30, 475-505. 
Sullivan, F. R. (2008). Robotics and science literacy: Thinking skills, science process skills and systems understanding. Journal of Research in Science Teaching. 45, 373-394.

Treise, D. \& Weigold, M. F. (2002). Advancing science communication: A survey of science communicators. Science Communication, 23, 310-322.

Trench, B. (2008). Towards an analytical framework of science communication models. In D. Cheng, M. Claessens, T. Gascoigne, J. Metcalfe, B. Schiele \& S. Shi, (Eds.) Communicating Science in Social Contexts: New models, new practices (pp.119-135).

Trevelyan, J. (1999). Redefining robotics for the new millennium. The International Journal of Robotics Research, 18, 1211-1223.

TwoCan Associates (2009). An Evaluation of the Process and Impact of Patient and Public Involvement in the Advisory Groups of the UK Clinical Research Collaboration. Final Report. London: UK Clinical Research Collaboration. Retrieved from http://www.ukcrc.org/pdf/PPI_Evaluation_Report_es.pdf

Ward, V., Howdle, P., \& Hamer, S. (2008) You and your body: A case study of bioscience communication at the University of Leeds. Science Communication, 30, 177-208.

Wilsdon, J. \& Willis, J. (2004). See-through Science: Why Public Engagement Needs to Move Upstream. London: Demos. Retrieved from http://www.demos.co.uk/files/Seethroughsciencefinal.pdf?1240939425

Wynne, B. (1996). May the sheep safely graze? A reflexive view of the expert-lay divide. In S. Lash, B. Szerszynski, \& B. Wynne (Eds). Risk, Environment and Modernity (pp.44-83). London: Sage.

Young, N. \& Matthews, R. (2007). Experts understanding of the public: Knowledge control in a risk controversy. Public Understanding of Science, 16, 123-144. 